\title{
A Sensor System Based on Semi-conductor Metal Oxide Technology for In Situ Detection of Coal Fired Combustion Gases
}

\author{
Funding Opportunity Announcement Number: DE-FC26-04NT42231
}

\section{Final Report}

\section{Sept. 2004 - 31 May 2007 \\ Prepared by \\ Sensor Research \& Development Corporation}

Author: Brent Marquis, Director of Technology

Date of issue: 31 May 2007

Contract \#: DE-FC26-04NT42231

Organization: Sensor Research and Development Corporation

17 Godfrey Drive,

Orono, ME 04473

Phone: 1-207-866-0100

Fax: 1-207-866-2055

\section{Disclaimer:}

This report was prepared as an account of work sponsored by an agency of the United States Government. Neither the United States Government nor any agency thereof, nor any of their employees, makes any warranty, express or implied, or assumes any legal liability or responsibility for the accuracy, completeness, or usefulness of any information, apparatus, product, or process disclosed, or represents that its use would not infringe privately owned rights. Reference herein to any specific commercial product, process, or service by trade name, trademark, manufacturer, or otherwise does not necessarily constitute or imply its endorsement, recommendation, or favoring by the United States Government or any agency thereof. The views and opinions of authors expressed herein do not necessarily state or reflect those of the United States Government or any agency thereof. 
Purpose: To provide a Final Report that details the progress since the last quarterly status report (Oct-Dec 2006) and summarizes the program's efforts, current status, and steps to move forward under the funded contract DE-FC26-04NT42231. This report is also written to satisfy the Jan-Mar 2007 quarterly status report. A separate Appendix to the Final Report is also being submitted that contains SRD proprietary information that is NOT for public distribution.
Abstract: Sensor Researc
phase program to dev
real-time detection, id
gases and perform fie
developed and selected
monoxide, carbon diox
and hydrogen chloride
prototype to function
at DOE approved facil
estimate the concentr
low false-alarm rates
Contents
1. Introduction 3

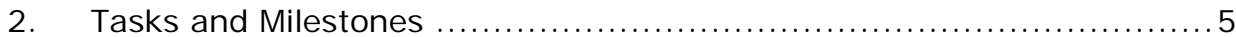

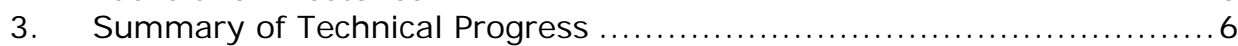

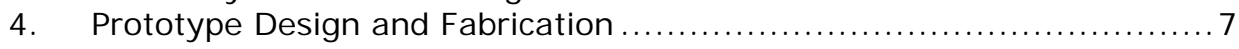

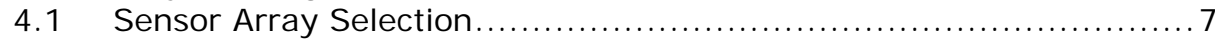

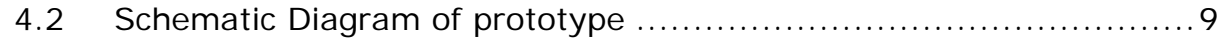

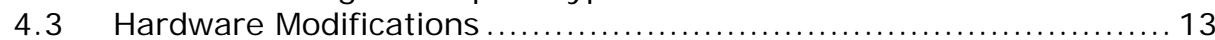

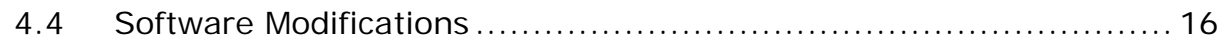

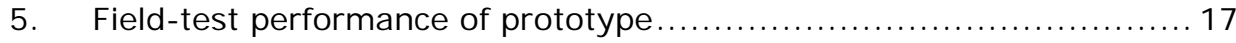

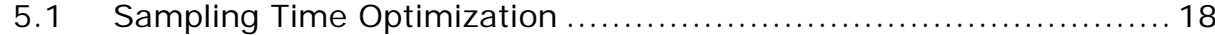

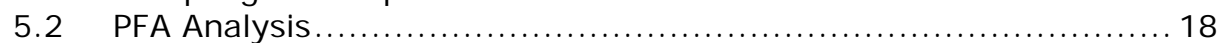

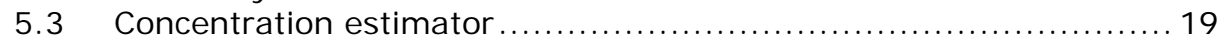

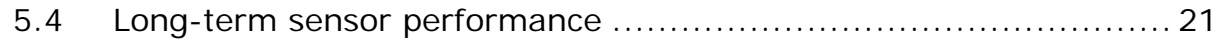

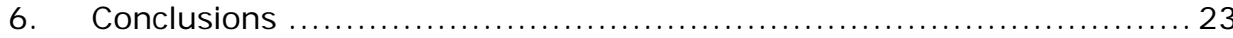




\section{Introduction}

Sensor Research and Development Corporation (SRD) proposed a two-phase program to develop a robust, autonomous prototype analyzer for in situ, real-time detection, identification, and measurement of coal-fired combustion gases and perform field-testing at an approved power generation facility. The prototype analyzer combines an array of chemically tailored Semi-conducting Metal Oxide (SMO) sensors with advanced signal processing and pattern recognition algorithms. SRD applied experience gained from the previous Department of Energy (DOE) funded effort: Developing SMO sensors to detect nitric oxide (NO), nitrogen dioxide $\left(\mathrm{NO}_{2}\right)$, ammonia $\left(\mathrm{NH}_{3}\right)$, sulfur dioxide $\left(\mathrm{SO}_{2}\right)$, carbon monoxide $(\mathrm{CO})$ and carbon dioxide $\left(\mathrm{CO}_{2}\right)($ Contract \# DE-AT26-99FT40611).

SRD developed automated gas delivery systems that simulate post-combustion gas streams generated in coalfired power plants. SRD performed significant validation of the simulated gas environments via GC/MS, TCD, Chemiluminescence, and FID analytical methods to ensure accuracy of the simulated conditions and validate sensor array response characteristics. Based on the sensor array's response characteristics, SRD also designed and implemented a gas-sampling system to extract slipstreams of the post-combustion gas stream at $>200^{\circ} \mathrm{C}$ to maintain in situ operation temperatures. The sampling system consisted of

1. Heat-controlled sample line from combustion system (maintain combustion stream temperature $\left.>200^{\circ} \mathrm{C}\right)$,

2. Sensor array sampling chamber,

3. Gas prefilters, flow controllers, and valves,

4. In-line temperature/humidity sensors, and

5. Venturi pump.

A LabVIEW-based hardware/software interface was developed to also serve as the data acquisition and control system for the testing of simulated flue gas. This LabVIEW interface was also made accessible via the WEB to allow SRD personnel to control test conditions from outside of SRD's facility to increase test productivity and to allow for field-testing parameters to be modified by SRD personnel from SRD's facility to cut down on travel time and costs.

SRD has also fabricated, conditioned, and tested over 200 different sensor material recipes. These sensors have been combined into an array to demonstrate capability for quantifying low levels of some constituents in flue gases with the necessary selectivity. In the first part of this program, SRD synthesized chemically tailored SMO sensors that focused kinetic reactions with target gases including $\mathrm{SO}_{2}, \mathrm{HCl}, \mathrm{NH}_{3}$, and $\mathrm{NO}_{2}$. 
The SMO sensors' parameters were optimized for operating in the post-combustion environment including preconditioning/annealing, operating temperature, film thickness, and catalysts/levels/concentrations. SRD developed software-based data pre-processing tools such as Principal Component Analysis (PCA) and Linear Discriminant Analysis (LDA) along with several classification algorithms including probabilistic statistics, support vector machines, and neural networks to more efficiently and effective process, analyze, and interpret the large volumes of sensor response data being generated.

SRD developed a field able prototype chemcial analyzer for in situ operation in the post-combustion of power generation systems and performed two trials of actual field-testing at PSDF's power generation facility located in Wilsonville, AL. The prototype integrated support systems around the sensor array and the signal processing and interpretation algorithms. The prototype operated autonomously for the duration of field-testing while providing real-time analysis of the post-combustion gas stream at $200^{\circ} \mathrm{C}$. A summary of the major tasks that were accomplished to build and field test the prototype chemcial analyzer are listed in Table 1.

Table 1: Program Tasks

\begin{tabular}{ll}
\hline Project Task \# & Description \\
\hline $\begin{array}{l}\text { Fabricate and condition novel metal } \\
\text { oxide(s)/catalyst(s) sensing films }\end{array}$ & $\begin{array}{l}\text { SRD synthesized chemically specific single and mixed metal oxide(s) with } \\
\text { select catalytic additives to enhance or inhibit sensor responses to target gases. }\end{array}$
\end{tabular}

Examine different SMO sensor operating temperature profiles

Evaluate SMO sensor responses to single combustion gases

Evaluate SMO sensor responses to combustion gas mixtures

Develop custom software algorithms to process, analyze, and interpret the sensor response data

Investigate various gas prefiltration strategies

Evaluate SMO sensor long-term performance characteristics
SRD will evaluate each SMO sensor under discrete and time-varying operating temperature profiles to determine the conditions that yield the most selective response signatures for each combustion gas.

The SMO sensors developed in Tasks 1-2 will be exposed to the selected combustion gases by SRD's custom-developed automated combustion gas simulation and delivery systems.

The SMO sensor arrays selected from Task 3 will be further analyzed for performance in mixtures of combustion gases.

SRD will adapt in-house sensor signal processing algorithms as necessary to improve sensor data processing and analysis, as well as maximize the prototype combustion gas monitoring system's ability to correlate sensor array responses to gas types and concentrations.

Each sensor's selectivity will be further improved by evaluating various "inline" and/or integrated (directly on sensor device) gas prefiltration strategies (i.e. catalysts, molecular sieves) to control which combustion gases are able to contact the sensor surfaces at any given time.

SRD will examine long-term SMO sensor performance characteristics, including response repeatability, stability of baseline and response sensitivity, package robustness, conditioning with time, and sensor lifetimes.

SRD will develop the necessary sampling system to deliver the high temperature $\left(100^{\circ}-800^{\circ} \mathrm{C}\right)$ combustion stream to the SMO sensor array.
Design and fabricate the prototype gassampling system 
Integrate SRD custom-developed SMObased test equipment into a single field testable prototype

Design and develop a field testable prototype sensor system
SRD will combine its SMO-based test and measurement equipment into a single system.

Identify field-test site

SRD will integrate the gas-sampling system (Task 8), consolidated SMO sensor support electronics (Task 9), signal processing algorithms (Task 5), and selected SMO sensor arrays (Task 4) into a single, field testable prototype.

With input and guidance from its DOE sponsor, SRD will select a field-test site to evaluate the prototype performance in an operating power plant.

Perform field tests with the prototype at a power generation plant (determined by SRD will test the prototype sensor system in situ at an operating power generation plant.

DOE sponsor)

\section{Tasks and Milestones}

Table 2 lists the major milestones and planned completion dates for the project's statement of work.

Table 2: Major Milestone Status

\begin{tabular}{|c|c|c|c|c|}
\hline Milestone Description & Baseline & Revised & Actual & Reason for Variance \\
\hline $\begin{array}{l}\text { Fabricated and tested at least one } \\
\text { unique sensor material for each } \\
\text { specific gas }\end{array}$ & $12 / 31 / 04$ & - & $12 / 15 / 04$ & Completed \\
\hline $\begin{array}{l}\text { Choose seven preliminary } \\
\text { prefiltration strategies to test }\end{array}$ & $12 / 31 / 04$ & - & $12 / 15 / 04$ & Completed \\
\hline 1st Quarterly Status Report 2004 & $12 / 15 / 04$ & - & $12 / 15 / 04$ & Completed \\
\hline $\begin{array}{l}\text { Identified an appropriate field study } \\
\text { site }\end{array}$ & $03 / 30 / 05$ & - & 03/30/05 & Completed \\
\hline $2^{\text {nd }}$ Quarterly Status Report 2005 & 03/30/05 & - & $03 / 30 / 05$ & Completed \\
\hline $\begin{array}{l}\text { Finished fabrication of field } \\
\text { prototype with at least } 6 \mathrm{SMO} \text { type } \\
\text { sensors }\end{array}$ & $6 / 30 / 05$ & - & $8 / 30 / 05$ & $\begin{array}{l}\text { Working with Frank Morton } \\
\text { Principal Engineer } \\
\text { Power Systems } \\
\text { Development Facility } \\
\text { (PSDF) }\end{array}$ \\
\hline 3rd Quarterly Status Report 2005 & $07 / 31 / 05$ & - & 08/15/05 & $\begin{array}{l}\text { Data collection and design } \\
\text { work }\end{array}$ \\
\hline $\begin{array}{l}\text { Finish the fabrication of the prototype } \\
\text { gas sampling system }\end{array}$ & $9 / 30 / 05$ & & $1 / 30 / 06$ & $\begin{array}{l}\text { Continuing work with } \\
\text { Southern Company Services }\end{array}$ \\
\hline $\begin{array}{l}\text { Completion and demonstration of } \\
\text { selectivity to single flue mixtures }\end{array}$ & $9 / 30 / 05$ & & $9 / 30 / 05$ & Completed \\
\hline
\end{tabular}




\begin{tabular}{|c|c|c|c|c|}
\hline Milestone Description & Baseline & Revised & Actual & Reason for Variance \\
\hline $\begin{array}{l}\text { Final selection of } 6 \text { to } 12 \mathrm{SMO} \text { sensor } \\
\text { array }\end{array}$ & $9 / 30 / 05$ & & $1 / 30 / 06$ & $\begin{array}{l}\text { Work for CO2 Selectivity } \\
\text { Needed }\end{array}$ \\
\hline $4^{\text {th }}$ Quarterly Status Report 2005 & $10 / 31 / 05$ & - & $1 / 10 / 06$ & $\begin{array}{l}\text { Delay in delivery of CO \& } \\
\text { CO2 gas bottles, data } \\
\text { processing, \& personnel } \\
\text { restructure }\end{array}$ \\
\hline 1st Quarterly Status Report 2006 & $1 / 30 / 06$ & & $1 / 30 / 06$ & Completed \\
\hline $2^{\text {nd }}$ Quarterly Status Report 2006 & $4 / 30 / 06$ & & $4 / 30 / 06$ & Completed \\
\hline $\begin{array}{l}\text { Combining the sensor array with } \\
\text { prefiltration, if needed }\end{array}$ & $3 / 30 / 06$ & & $6 / 30 / 06$ & Testing completed \\
\hline $\begin{array}{l}\text { Completion and demonstration of } \\
\text { selectivity to multiple flue mixtures }\end{array}$ & $3 / 30 / 06$ & & $3 / 30 / 06$ & Completed \\
\hline $\begin{array}{l}\text { Completion of Prototype for Field } \\
\text { testing }\end{array}$ & $06 / 31 / 06$ & & 08/31/06 & Parts backordered \\
\hline $3^{\text {rd }}$ Quarterly Status Report 2006 & $7 / 30 / 06$ & & $7 / 30 / 06$ & Completed \\
\hline $4^{\text {th }}$ Quarterly Status Report 2006 & $10 / 30 / 06$ & & $11 / 15 / 06$ & $\begin{array}{l}\text { Prepare for Field Testing } \\
\text { then Report Preparation }\end{array}$ \\
\hline Completion of Field Testing I & $12 / 15 / 06$ & $12 / 15 / 06$ & $12 / 07 / 06$ & $\begin{array}{l}\text { Field Testing was stopped } \\
\text { early due to operations were } \\
\text { difficult with the high } \\
\text { sodium lignite coal. }\end{array}$ \\
\hline $1^{\text {st }}$ Quarterly Status Report 2007 & $1 / 30 / 06$ & - & $1 / 26 / 06$ & Completed \\
\hline Completion of Field Testing II & $01 / 31 / 07$ & & $3 / 26 / 07$ & $\begin{array}{l}\text { Delay in testing at PSDF } \\
\text { (outside of SRD's control) }\end{array}$ \\
\hline Final Program Report 2007 & $4 / 30 / 07$ & June 30, 2007 & June 15, 2007 & $\begin{array}{l}\text { Processing results from } \\
\text { Field Tests }\end{array}$ \\
\hline
\end{tabular}

\section{Summary of Technical Progress}

During the last period of this program, SRD has focused on improving the performance of the field able prototype based on feedback data obtained from testing at PSDF's power plant system during the month of Dec. 2006. These tests have enabled SRD to make changes to the hardware and software of the prototype analyzer to provide improved performance for January 2007 field tests also performed at PSDF's power plant.

Hardware changes include,

- Installation of knockout tubes to remove water condensation from flow path

- Installation of valves without any plastics in them due to high temperature operation

- Improved line-heating to mitigate cold-spots which in turn minimizes condensation points

- Installation of in-line filters for instrument air to remove fly ash particulates 
Software changes include,

- Adjusting hit detection algorithm parameters to eliminate false positive nuisance alarms.

- Training on data measured at PSDF and validating it on later experiments at PSDF.

- Providing concentration estimates for quantitation algorithms

SRD has analyzed the experiments run at PSDF and in a majority of the test (>96\%) has correctly classified the gas combinations to which the sensors were subjected. The performance of the prototype at PSDF, as indicated by the probability of false alarm (PFA) has also been determined. In addition, SRD has also added the ability to provide concentration estimates and has also tabulated the results of these estimates in comparison with the true concentrations of the flue-gas constituents.

\section{Prototype Design and Fabrication}

\subsection{Sensor Array Selection}

Over the course of 1 year spanning $1^{\text {st }}$ Quarter of 2005 to the $4^{\text {th }}$ quarter of 2005, SRD has developed and tested over 170 new metal oxide films with chemistries targeting sensing reactions with $\mathrm{SO}_{2}, \mathrm{NO}_{2}, \mathrm{HCl}, \mathrm{CO}, \mathrm{CO}_{2}$ and $\mathrm{NH}_{3}$.

The work done during the $1^{\text {st }}$ and $2^{\text {nd }}$ quarter of 2006 was focused more towards making sensors that were more selective and sensitive to carbon monoxide and carbon dioxide. In addition to the selection of new sensors, much of the work in that quarter was involved with testing the sensors under conditions designed to mimic those at the field-test site (i.e PSDF). SRD has shown that testing at $250{ }^{\circ} \mathrm{C}$ to single gas mixtures showed little difference in the performance of the sensors.

A 10-sensor array was selected to support the development of a prototype chemcial analyzer to be field-tested. Figure 1 presents the spider-charts of the sensor array's responses to each target gas at concentrations specified by PSDF. As can be seen from the spider-charts, each gas has a distinct spider chart pattern, which is a strong indication that the signal processing and algorithms will be able to distinguish between each gas type based on the sensor array response data. 


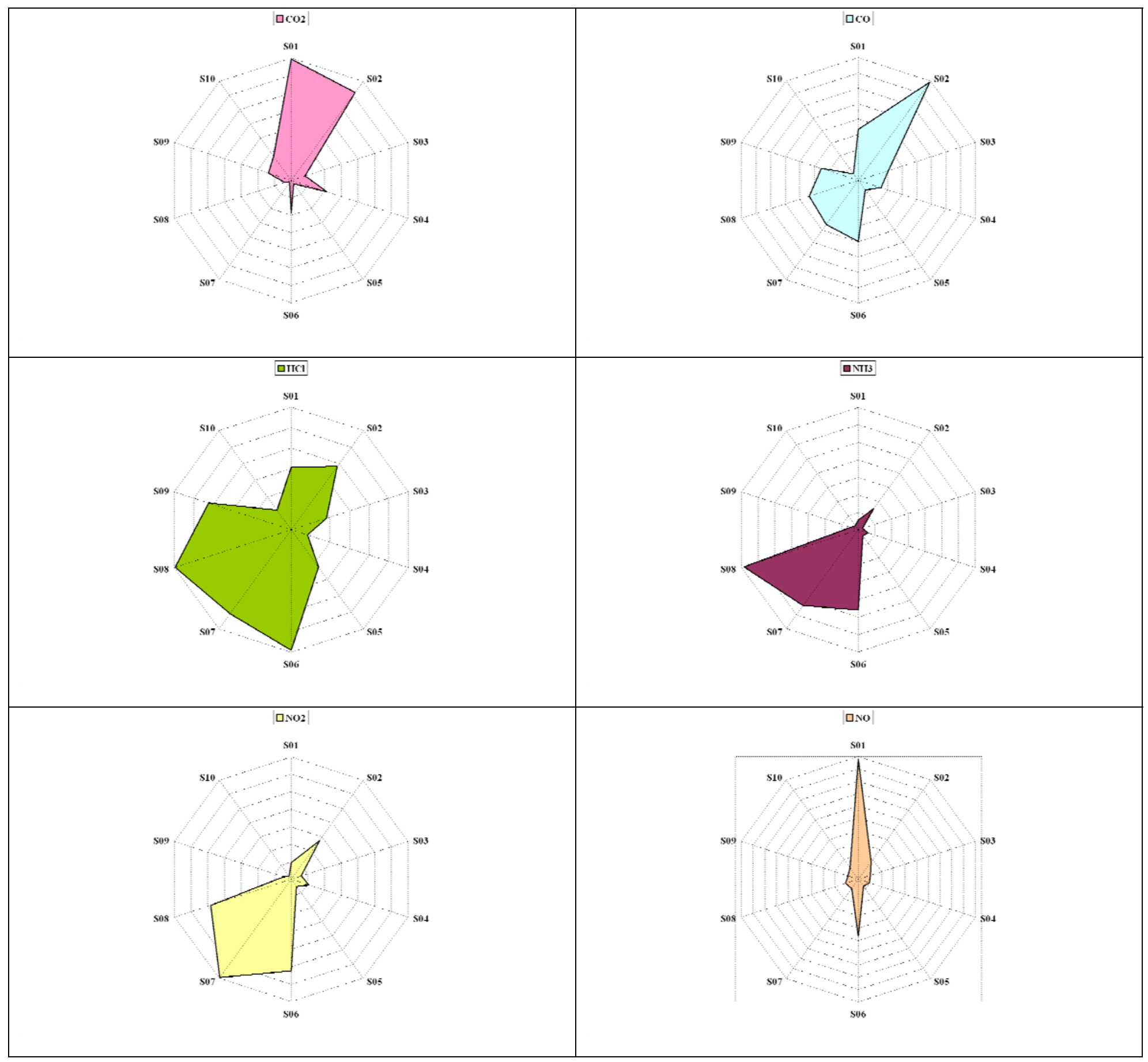




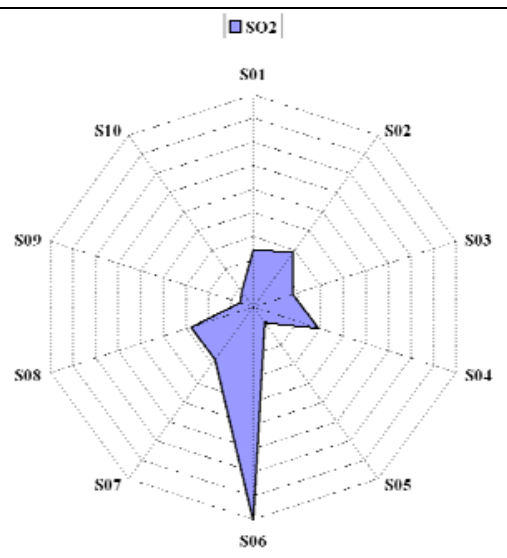

Figure 1: Spider Charts of sensor array responses to individual post-combustion gases including $\mathrm{CO}, \mathrm{CO}_{2}, \mathrm{NO}, \mathrm{NO}, \mathrm{HCl}$, $\mathrm{NH}_{3}, \mathrm{SO}_{2}$.

\subsection{Schematic Diagram of prototype}

Figure 2 shows a photograph of SRD's chemical analyzer prototype that was used during field-testing. A photograph of the front and rear of the prototype is shown in Figure 3 and Figure 4, respectively. The prototype has a gas inlet on the front and gas outlet on the back. The prototype requires a 120VAC cord for the prototype and the Laptop. There is also a USB cable required for the prototype and laptop to communicate back and forth. Figure 5 provides a view of the internal components of the prototype including support electronics, power supply, data acquisition digital and analog I/Os, and sensor array chamber.

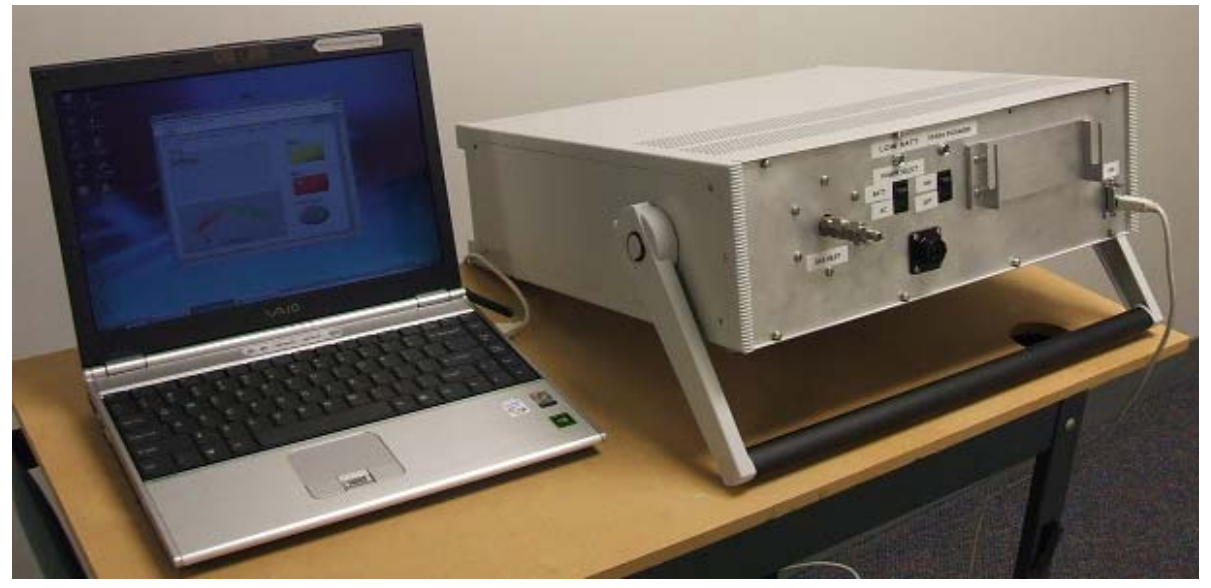

Figure 2. SRD'S NETL Prototype for Field-Testing. 


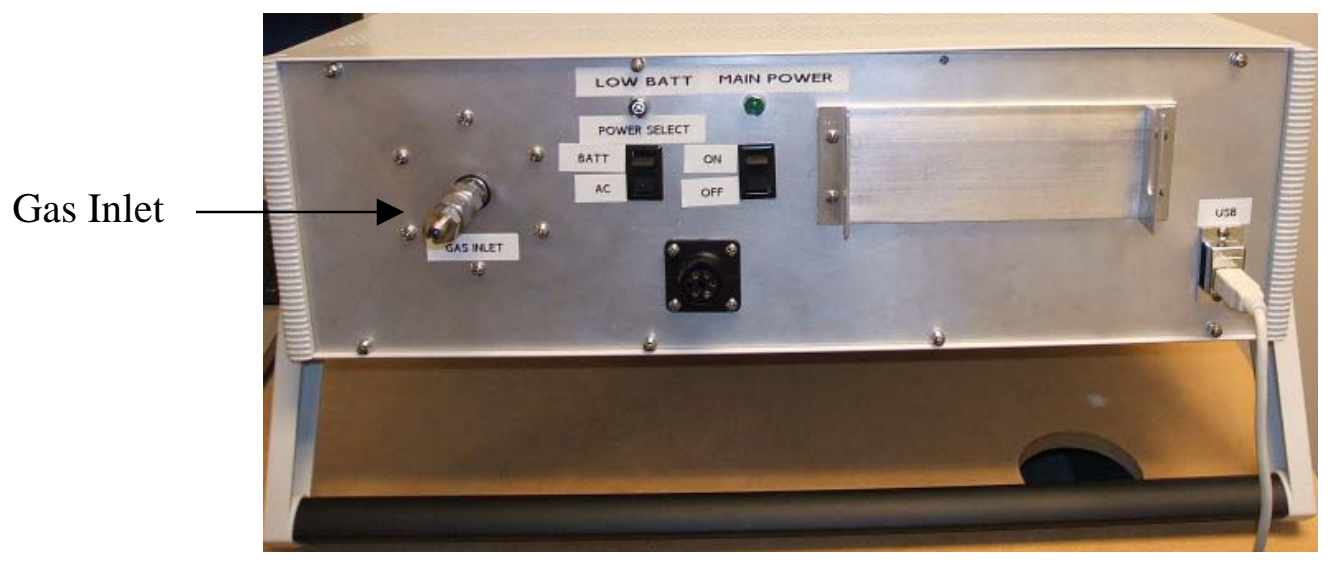

Figure 3. Front Panel of SRD's NETL Prototype

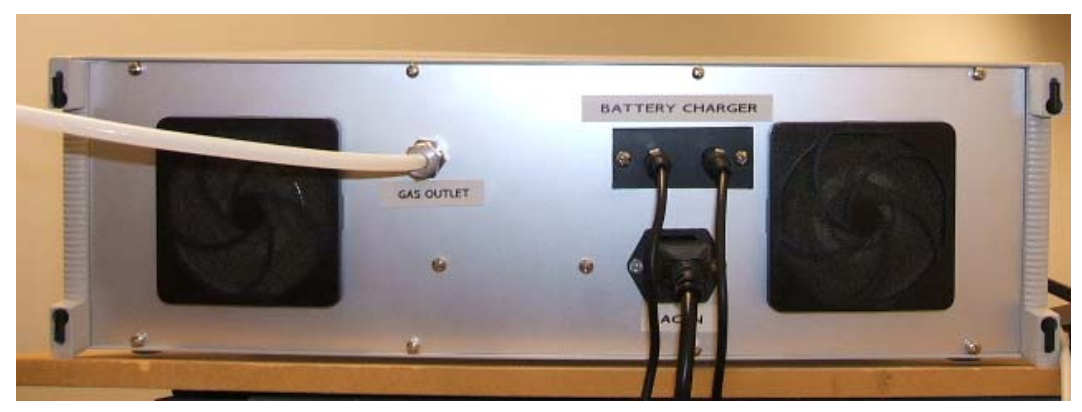

Figure 4. Photograph of the Back Panel of SRD's NETL Prototype 


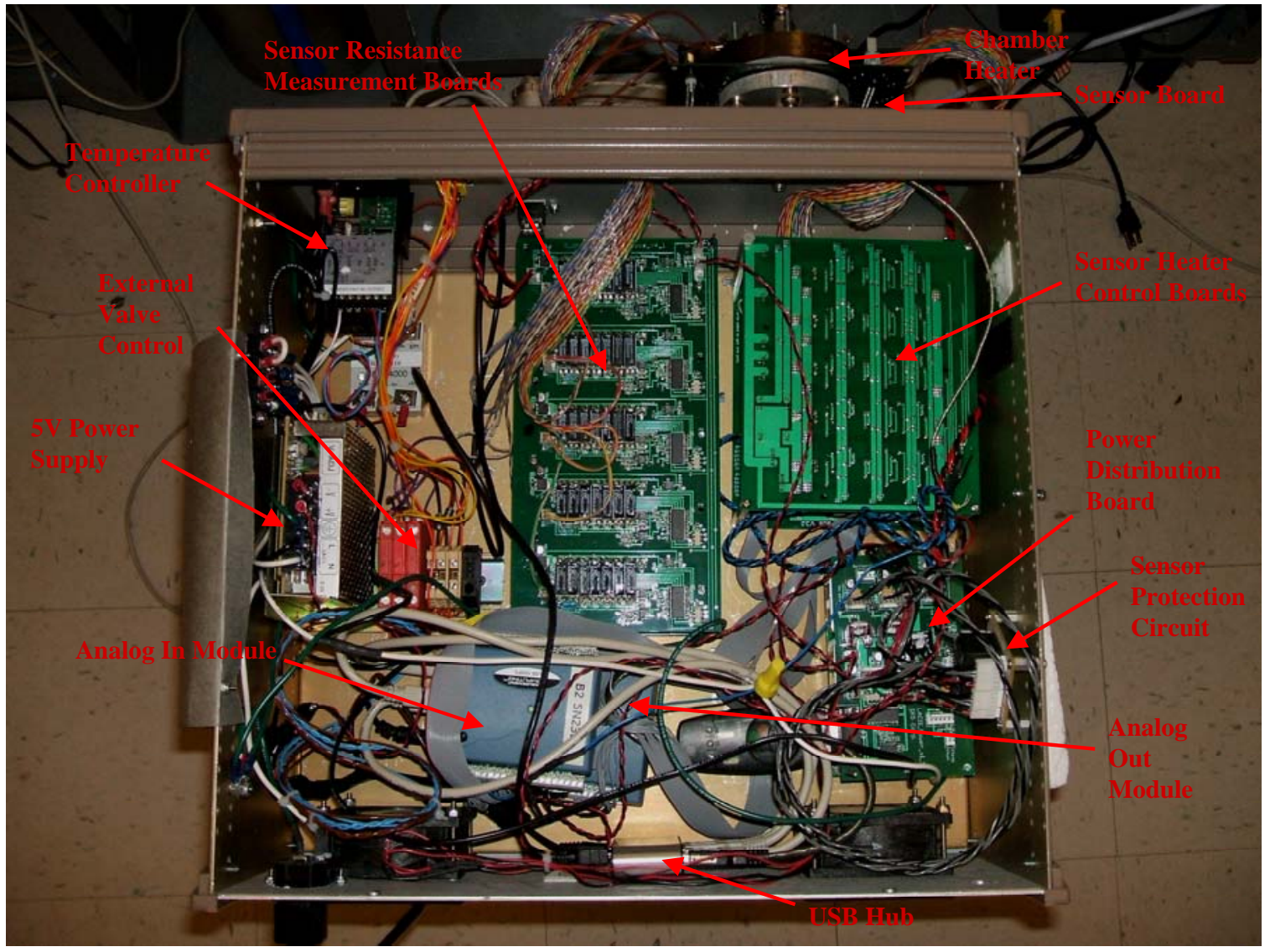

Figure 5. Inside View of SRD's NETL Prototype

Figure 6 represents a functional schematic of SRD's chemical analyzer prototype. The data lines are indicated along with power distributions to between subsystems.

The main prototype modules are the SMO sensor module, sensor heater module, sensor resistance measurement module and power distribution, communication module. The entire operation of the prototype module is controlled by the laptop LabView interface. This interface controls the power distribution and heater module. The sensor heater module monitors and regulates the temperature of operation of the sensor materials based on input from the laptop. Gas is delivered to the sensor module via the rotary pump. The changes in the sensor resistance due to interaction of material with gas is recorded by the sensor resistance measurement module and passed onto the power distribution and communication module. This module transfers the data to the laptop via a USB connection for processing. 


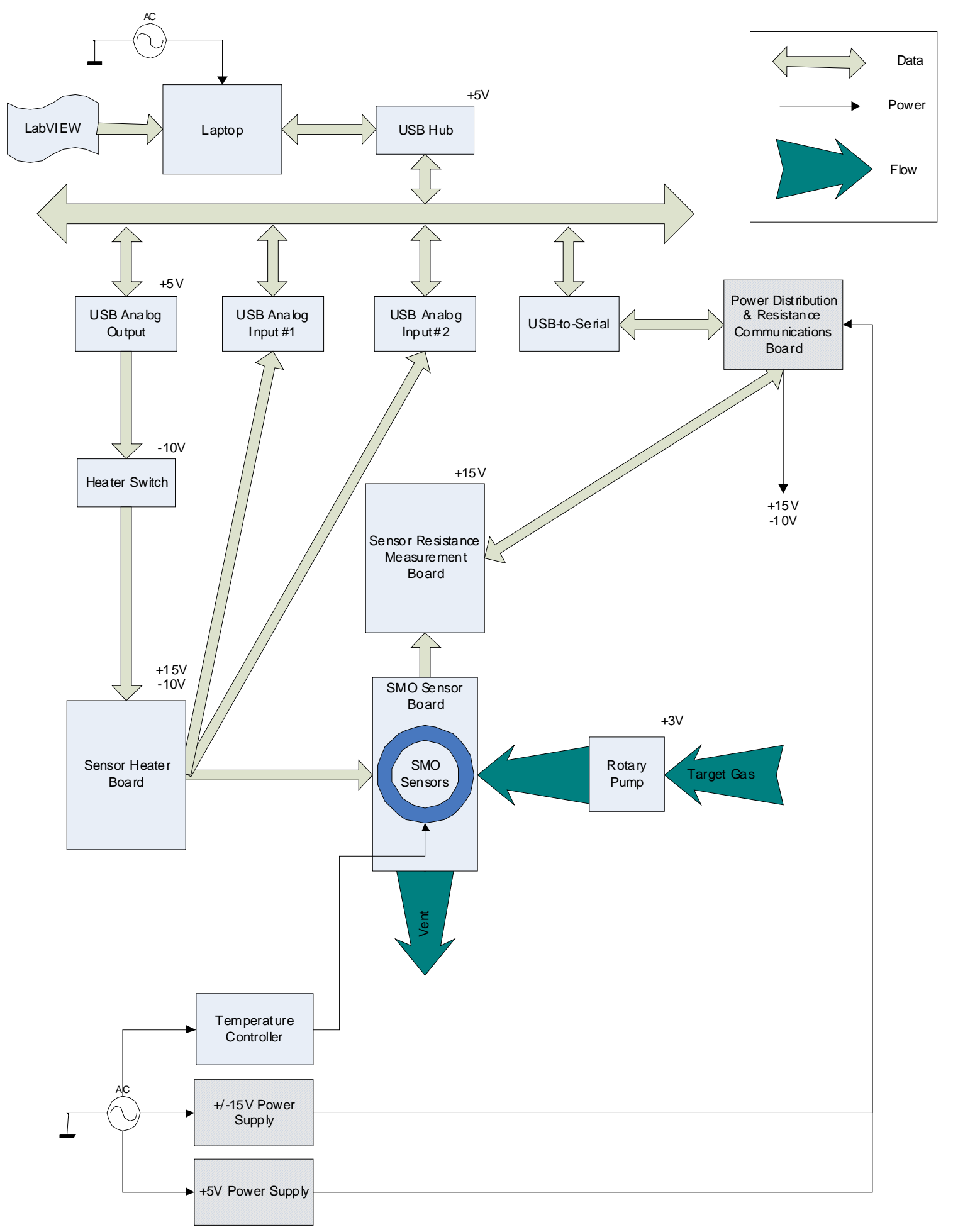

Figure 6 Functional schematic of SRD's NETL Prototype including 1) Data, 2)Power, \& 3) Gas Flow. 


\subsection{Hardware Modifications}

With the development of the sensor array being in its final stages for completion, in the $3^{\text {rd }}$ quarter of 2006, SRD focused on the development of the prototype chemcial analyzer that could be deployed for field-testing at PSDF.
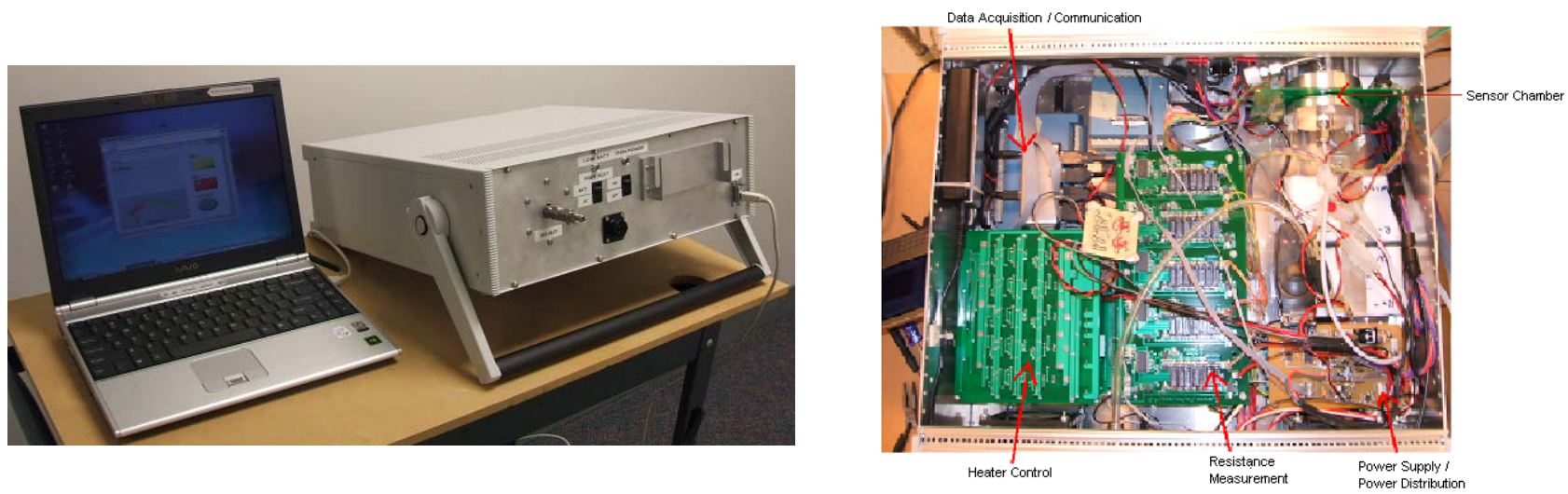

Figure 7 View of SRD's prototype chemcial analyzer along with interior view.

Figure 7 shows photographs of the prototype chemcial analyzer along with an interior view to show the electronic components inside the prototype.

During testing conducted at SRD in the $4^{\text {th }}$ quarter 2006, SRD discovered that the temperature of the sample line decreased from the outlet of the oven (to represent the heated sample line in the field) to the sensor chamber. This temperature decrease altered the sensor baselines and response characteristics due to the gas composition variation at lowered temperature. As a result, a mica band heater was placed around the sensor chamber to ensure that the gas was at $205^{\circ} \mathrm{C}$, the same temperature as the sample line. This heater coupled with insulation at the sample interface point ensured constant temperature of sampled gas. In addition, a 3-way valve was introduced by SRD to aid in switching from air to effluent gas stream.

During the first round of field-tests performed back in December 2006, SRD had encountered several hardware related issues with the operating their prototype chemcial analyzer at PSDF. Table 3 details the field issues along with the cause and resolutions. 
Table 3 Issues and actions taken to resolve said issues.

\begin{tabular}{|l|l|l|}
\hline \multicolumn{1}{|c|}{ Field Issue } & \multicolumn{1}{c|}{ Cause } & \multicolumn{1}{c|}{ Immediate Resolution } \\
\hline Water Condensation & Cooling of Post Combustion Gas & Knock Outs post heating lines \\
\hline $\begin{array}{l}\text { Molecular Sieves in Instrument } \\
\text { Clogged Sample Valve }\end{array}$ & $\begin{array}{l}\text { So filtration in Instrument Air } \\
\text { Condensation }\end{array}$ & 20 micron and 10 micron filters \\
\hline Sample Salt / Soot Precipitation & Cold spots in Sampling lines & Better heating on sample lines \\
\hline Over Heated Sample Valve & $\begin{array}{l}\text { Due to heating plastic in Valve turn } \\
\text { brittle }\end{array}$ & $\begin{array}{l}\text { Used different Valve type - no } \\
\text { plastics }\end{array}$ \\
\hline File Write Error & $\begin{array}{l}\text { Labview@ / Fileshare read write } \\
\text { error }\end{array}$ & $\begin{array}{l}\text { Removed automatic Fileshare - } \\
\text { manual download }\end{array}$ \\
\hline Communications with Unit & Cellular connection lost & $\begin{array}{l}\text { Reboot/ Field help - no permanent } \\
\text { resolution - phone line next time }\end{array}$ \\
\hline
\end{tabular}

In addition to the resolution of the issues mentioned in Table 3, SRD had to incorporate further changes in the prototype design primarily to enable connection to equipment/sample line at PSDF. PSDF had installed a heated sampling probe for stack/flue gas sampling. It consisted of an extension tube (distance set to the midpoint of the duct), a heater (set at 150-200 degrees C), a ceramic filter, and a blowback system (not used for our application). The temperature of the extension tube and surrounding gas were the same (no condensation would be able to occur). The temperature of the heater/filter was considerably higher than that of the gas, and the heated portion of the probe was approximately at the same temperature as the heated line. This eliminated any "cold" spots and condensation (one of the main problems SRD experienced with the first beta test). This type of heated probe would be used on monitoring units of any type (CO2, NOx, mercury, etc.). The probe system had a blow back feature that was not used for the following reasons:

1. the extension was equipped with a filter of its own

2. the particulate loading of this stream is very low

3. the effects of the blow-back on the prototype were unknown. 

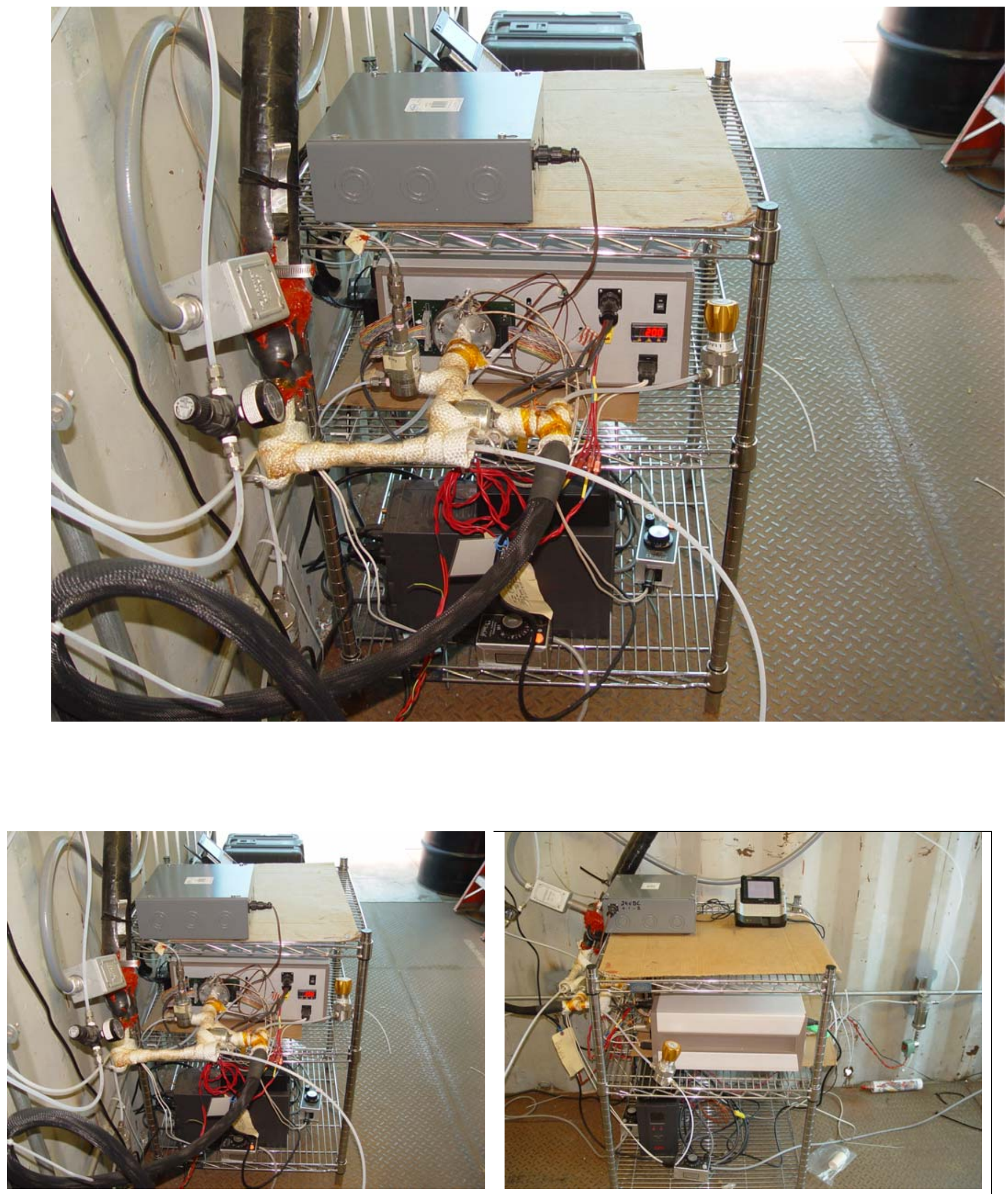

Figure 8 Modified prototype design used at PSDF for March-April 2007 field test. 


\subsection{Software Modifications}

\subsubsection{LABVIEW software}

During the $3^{\text {rd }}$ quarter of 2006, SRD began to work on making software changes to the prototype to ready the prototype for field-testing. The entire operation of the prototype was controlled by LABVIEW.

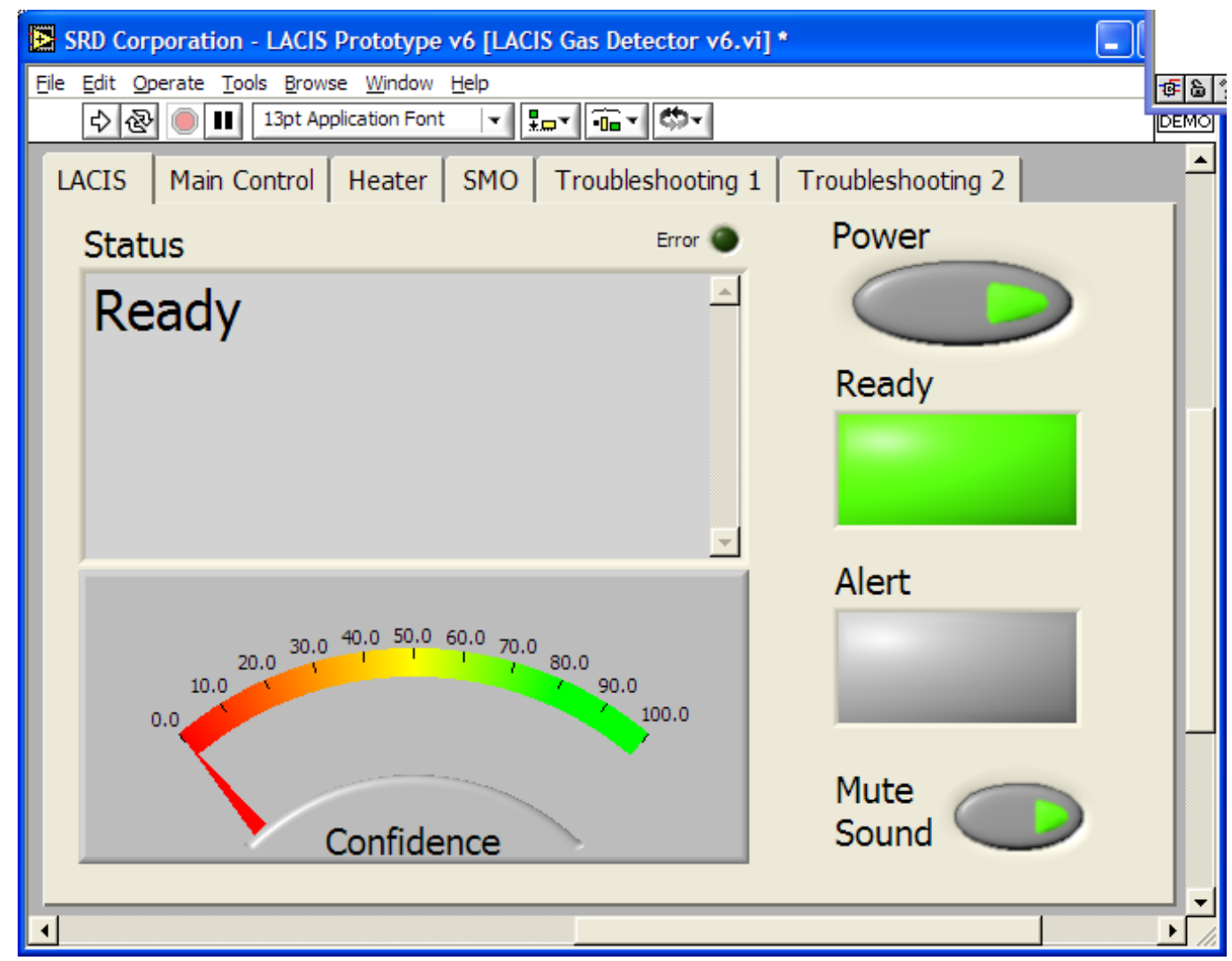

Figure 9 LABVIEW interface to the prototype.

Figure 9 shows the LABVIEW interface used to control the operations of the prototype. In addition to the control of the prototype, the interface was also used to display status messages, display the gases which were detected and control the switching of the 3-way valve used to change flow to prototype from gas stream to air.

\subsubsection{Signal Processing Modifications}

In the $3^{\text {rd }}$ quarter of 2006, SRD had implemented signal-processing algorithms to perform hit-detection (process of determining if the sensor response was due to a gas exposure or merely noise) and a variety of classification algorithms (K-nearest neighbours, Neural Networks, SVM-second degree polynomial, SVM-third degree polynomial, SVM-RBF) to identify the type of gases present in the mixtures. 
Detection Threshold

The minimum value a sensor has to deviate from the baseline, in order to consider the deviation as a potential hit.

The time duration during which a deviation from baseline must

Response Requirement be greater than the threshold in order to categorize the deviation as an hit.

Trigger Number

The minimum number of sensors that need to register the deviation above the threshold.

Weight Threshold

The value, which the combined deviations of the sensors must exceed in order to ascertain a hit.

Table 4 shows a list of the critical hit-detection parameters used currently in the prototype chemcial analyzer during the second round of field-tests performed at PSDF in March-April 2007.

For the $3^{\text {rd }}$ and $4^{\text {th }}$ quarters of 2006, SRD's classification algorithm functioned very effectively with no modifications required. However, for the $1^{\text {st }}$ quarter of 2007, SRD had indicated that it would incorporate a concentration estimator into the signal processing algorithms. To do so, SRD had initiated changes to the training algorithm. The approach to training involved using sensor responses along with the corresponding IR measurement data of concentrations to categorize the response as a distinct class. Any additional concentration measurements were categorized into new and separate classes. This data was then used to train the prototype and during the testing phase, the classification of the gas combination also determined the concentration of the constituent gases. One of the main issues that SRD has identified is that for robust performance, a very rich training database is required, which can only be obtained once SRD is able to train in a range of representative environments.

The following sub-section will detail the performance of SRD's prototype chemcial analyzer during the second round of field-tests performed at PSDF during March and April 2007.

\section{Field-test performance of prototype}

Performance of the prototype is achieved by computing the probability of false alarm (PFA) and also the accuracy of the estimates of concentration. The following subsections detail the prototype's performance during field-tests conducted in March-April 2007. 


\subsection{Sampling Time Optimization}

In the report filed for the $1^{\text {st }}$ quarter of 2007 , SRD had proposed to optimize the sampling time of the prototype. To achieve this, SRD initially started running tests initially at 1-minute gas exposure and 8 minute recovery. The data was then collected over the course of a couple of hours and then processed to secure information regarding the minimum time required for the sensors to achieve full recovery. Based on this, the recovery time for the data was set to be 2.5 minutes. Thus the prototype samples the gas every 3.5 minutes and thus outputs gas constituents and their concentrations every 3.5 minutes. The 1-minute exposure is, in large part, required based on the signal processing algorithms processes, which could eventually be reduced to 10's of seconds.

\subsection{PFA Analysis}

Performance of the prototype was measured by computing the probability of false alarm (PFA) and probability of missed detection (also known as false negative rate) of the system. The performance of the prototype is mainly categorized into 3 parts,

1. False Positive Rate

The false positive rate is measured by the occurrence of either or both of following 2 events,

a) Incorrect classification - the prototype correctly detects the presence of the gas but misclassifies the gas.

b) False alarm due to noise - the prototype incorrectly indicates that a gas is present when no gas present. This normally arises due to deviations caused in array responses by noise or sudden changes in environmental conditions such as humidity and temperature. The environmental effects have been mitigated with the addition of humidity and temperature sensors serving as real-time feedback into the sensor array and algorithms.

2. False Negative Rate

The false negative is a measure of the probability of the prototype to completely miss detecting and classifying a gas i.e. the prototype states that there is no gas present when there is a gas present. This is often a more critical measure of the performance of the prototype than false positive rate, as ideally we would want the prototype to alert us to the presence of any gas.

Of course an ideal chemical analyzer would perform with $0 \%$ false negative rate and false positive rate. The following sub-sections will discuss the performance of SRD's prototype chemcial analyzer during field-tests performed at PSDF.

SRD analyzed the data collected at PSDF during March-April 2007, to assess the performance of the prototype by computing the performance measures detailed above. At the site, the flue gas comprised of a mixture of carbon monoxide (20-200ppm with an average value of $30 \mathrm{ppm}$ ), carbon dioxide (3000-10000 ppm with an 
average of 8000 ppm), sulfur dioxide (100-900 ppm with an average of 550 ppm), nitrogen oxide (40-500 ppm with an average of $350 \mathrm{ppm}$ ) and nitrogen dioxide (0-5ppm). Ammonia and hydrogen chloride were introduce into the sample at regular intervals by external feeds at $80 \mathrm{ppm}$ each. These gases and concentrations were delivered and validated per IR measurements taken by PSDF personnel. Table 5 gives the probability of false alarm (PFA) for hit-to-hit results made during the field-testing phase. As can be seen from the above table, SRD's prototype chemical analyzer performed for 4 weeks with a false alarm rate of $3.5 \%$ with $0 \%$ false negatives and $0 \%$ false triggers or nuisance alarms.

Table 5 PFA table on second-to-second basis

\begin{tabular}{|c|c|c|c|c|c|c|c|c|c|}
\hline Analyte & $\begin{array}{c}\text { Average } \\
\text { Hit } \\
\text { Detection } \\
\text { Time } \\
\text { [Sec] }\end{array}$ & $\begin{array}{c}\text { Average Gas } \\
\text { Identification } \\
\text { Time [Sec] }\end{array}$ & $\begin{array}{c}\text { Total } \\
\text { number } \\
\text { of hits } \\
\text { classified }\end{array}$ & $\begin{array}{c}\text { Total } \\
\text { number of } \\
\text { hits } \\
\text { misclassified }\end{array}$ & $\begin{array}{c}\text { Total } \\
\text { number } \\
\text { of false } \\
\text { alarms }\end{array}$ & $\begin{array}{c}\text { False } \\
\text { Negative } \\
\text { Rate [\%] }\end{array}$ & $\begin{array}{c}\text { False } \\
\text { Positive } \\
\text { Rate [\%] } \\
\text { (Classification) }\end{array}$ & $\begin{array}{c}\text { False } \\
\text { Positive } \\
\text { Rate [\%] } \\
\text { (Hit } \\
\text { detection) }\end{array}$ & $\begin{array}{c}\text { False } \\
\text { Alarm } \\
\text { Rate } \\
{[\%]}\end{array}$ \\
\hline $\begin{array}{c}5 \text { gas } \\
\text { combination } \\
\text { of } \mathrm{CO}, \mathrm{CO} 2, \\
\mathrm{SO}, \mathrm{NO} \text { and } \\
\mathrm{NO} 2\end{array}$ & 16 & 19 & 2856 & 0 & 0 & 0 & 0 & 0 & 0 \\
\hline $\begin{array}{c}6 \text { gas } \\
\text { combination } \\
\text { of } \mathrm{CO}, \mathrm{CO} 2, \\
\mathrm{SO}, \mathrm{NO}, \\
\mathrm{NO} 2 \text { and } \\
\mathrm{NH} 3\end{array}$ & 18 & 21 & 1020 & 51 & 0 & 0 & 5 & 0 & 5 \\
\hline $\begin{array}{c}6 \text { gas } \\
\text { combination } \\
\text { of } \mathrm{CO}, \mathrm{CO} 2, \\
\mathrm{SO}, \mathrm{NO}, \\
\mathrm{NO} 2 \text { and } \\
\mathrm{HCl}\end{array}$ & 17 & 21 & 1020 & 57 & 0 & 0 & 5.6 & 0 & 5.6 \\
\hline Avg. & & & & & & & & & 3.53 \\
\hline
\end{tabular}

\subsection{Concentration estimator}

There are two metrics of performance for evaluating the prototype. The first is the probability of false alarm (PFA), which was presented above at $3.5 \%$ on a hit-to-hit basis in the previous section. The second metric is the accuracy of the estimates returned by the prototype. 
Table 6 Concentration profiles at PSDF and profiles in the training data.

\begin{tabular}{|c|c|c|}
\hline Chemical Name & $\begin{array}{c}\text { Concentration @ PSDF } \\
(\mathrm{ppm})\end{array}$ & $\begin{array}{c}\text { Discrete Concentration in } \\
\text { prototype's database } \\
(\mathrm{ppm})\end{array}$ \\
\hline Carbon monoxide (CO) & $20-200$ & 50,100 and 150 \\
\hline Carbon dioxide (CO2) & $3000-10000$ & 4500,9000 and 12000 \\
\hline Sulfur dioxide (SO2) & $100-900$ & 10,300 and 500 \\
\hline Nitrogen Oxides (NOx) & $40-500$ & 30,300 and 400 \\
\hline Ammonia (NH3) & 80 & 50 \\
\hline Hydrogen chloride (HCl) & 80 & 50 \\
\hline
\end{tabular}

Table 6 lists the concentration profiles that were recorded at PSDF along with the discrete ranges in the training data of SRD's prototype. Due to the lack of a sufficiently rich training database, the prototype does not have the ability to give concentration estimates in a continuous range but rather can only output discrete values of the concentration. Table 7 compares the actual concentrations measured by PSDF, with the IR, with the concentrations estimated by SRD's prototype. With the information in Table 6 and Table 7, it is evident that SRD's prototype provides relatively accurate concentration estimation when compared with the IR measurement data.

Table 7 Comparison of true values of concentration and estimates returned by the prototype.

\begin{tabular}{|c|c|c|}
\hline Chemical Name & $\begin{array}{c}\text { True Concentration @ } \\
\text { PSDF (ppm) }\end{array}$ & $\begin{array}{c}\text { Estimated } \\
\text { Concentration } \\
\text { by prototype } \\
\text { (ppm) }\end{array}$ \\
\hline $\begin{array}{c}\text { Carbon monoxide } \\
\text { (CO) }\end{array}$ & 20 & 50 \\
\hline $\begin{array}{c}\text { Carbon monoxide } \\
\text { (CO) }\end{array}$ & 40 & 50 \\
\hline $\begin{array}{c}\text { Carbon monoxide } \\
\text { (CO) }\end{array}$ & 120 & 100 \\
\hline $\begin{array}{c}\text { Carbon dioxide } \\
\text { (CO2) }\end{array}$ & 3000 & 4500 \\
\hline
\end{tabular}




\begin{tabular}{|c|c|c|}
\hline $\begin{array}{l}\text { Carbon dioxide } \\
\text { (CO2) }\end{array}$ & 7500 & 9000 \\
\hline $\begin{array}{l}\text { Carbon dioxide } \\
\text { (CO2) }\end{array}$ & 10000 & 12000 \\
\hline $\begin{array}{l}\text { Sulfur dioxide } \\
\text { (SO2) }\end{array}$ & 100 & 300 \\
\hline $\begin{array}{l}\text { Sulfur dioxide } \\
\text { (SO2) }\end{array}$ & 400 & 500 \\
\hline $\begin{array}{l}\text { Sulfur dioxide } \\
\text { (SO2) }\end{array}$ & 900 & 500 \\
\hline $\begin{array}{l}\text { Nitrogen Oxides } \\
\text { (NOx) }\end{array}$ & 40 & 30 \\
\hline $\begin{array}{c}\text { Nitrogen Oxides } \\
\text { (NOx) }\end{array}$ & 350 & 300 \\
\hline $\begin{array}{l}\text { Nitrogen Oxides } \\
\text { (NOx) }\end{array}$ & 500 & 400 \\
\hline Ammonia (NH3) & 80 & 50 \\
\hline $\begin{array}{l}\text { Hydrogen chloride } \\
\text { (HCl) }\end{array}$ & 80 & 50 \\
\hline
\end{tabular}

\subsection{Long-term sensor performance}

SRD performed long-term tests by exposing the sensor array while evaluating the stability in baseline and response kinetics. Figure 10 and Figure 11 show the robustness of $\mathrm{SnO}_{2}$ sensors when subjected to prolonged testing over the course of several weeks to $\mathrm{NO}, \mathrm{SO}_{2}$, and $\mathrm{CO}$. The tests involved both long-term exposures and also short-term exposures done at regular intervals over a long period of time. From Figure 10 and Figure 11, it is evident that long-term testing of gases in lab-based environment showed that the sensors were stable responded with repeatable kinetics over time. 


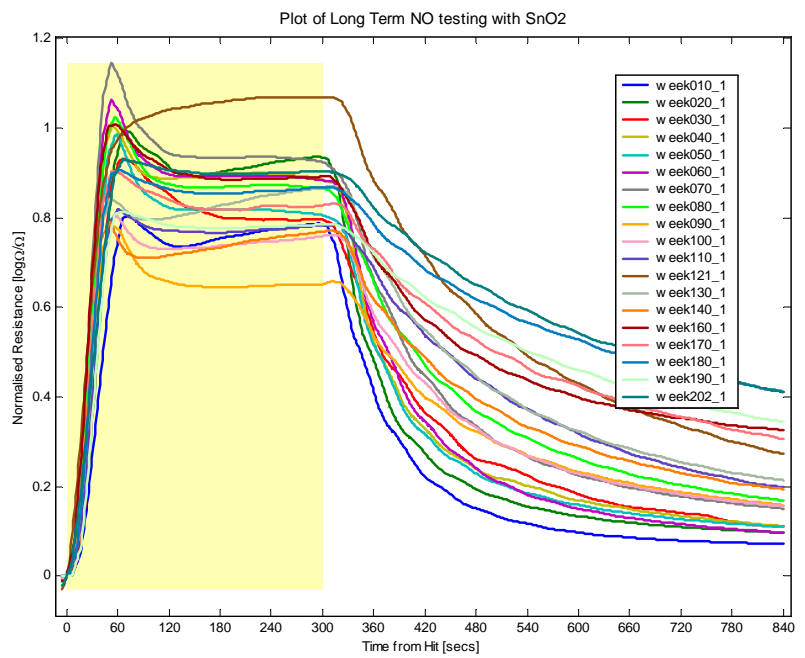

Figure 10 Long-term in-house testing of $\mathrm{SnO}_{2}$ sensors to $\mathrm{NO}$ gas.

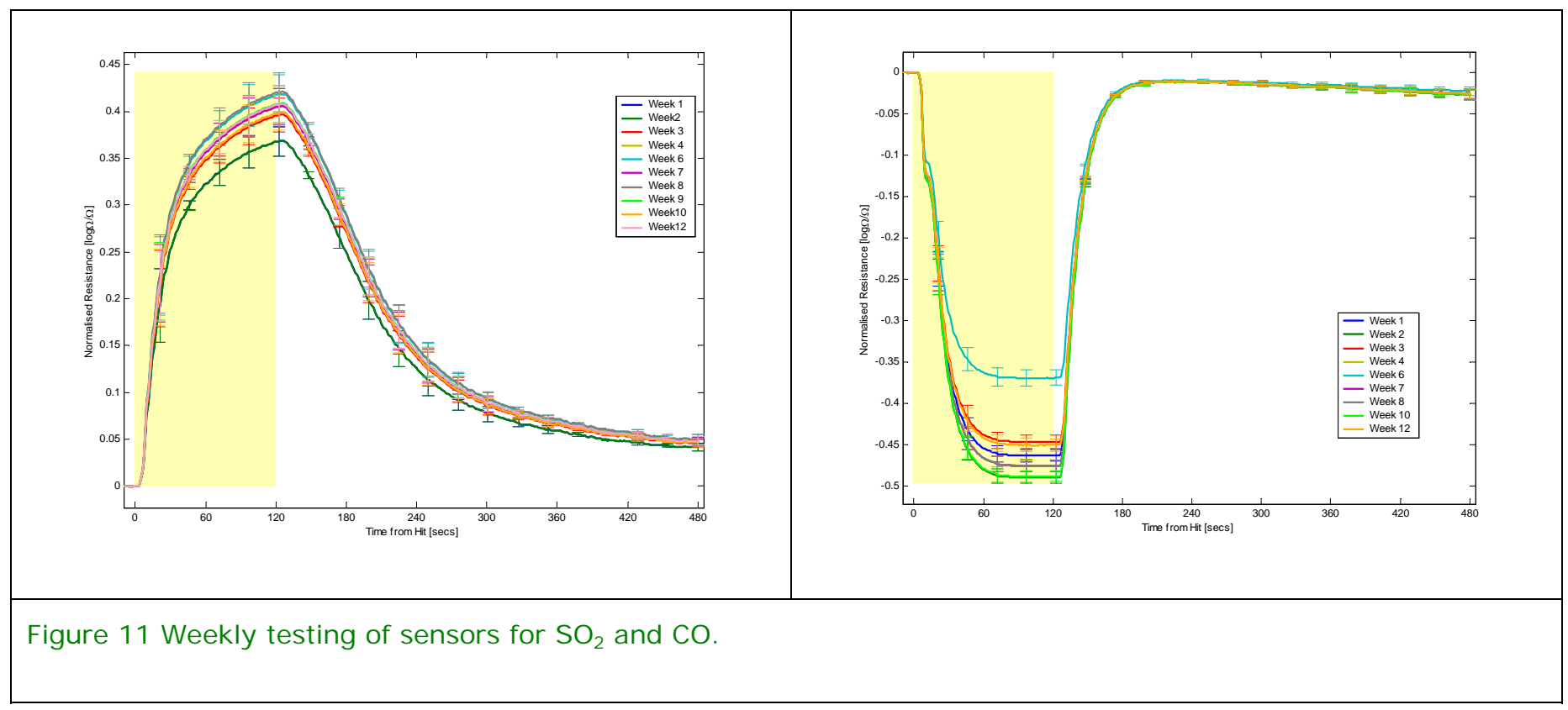

In order to test the robustness of the sensor array, SRD performed comparative testing before field-testing, during field-testing, post field-testing, back to field-testing, and back to post-field testing during the MarchApril 2007 field test trial. Prior to the field-testing, the sensor array was exposed to a variety of gas mixtures at SRD's facility to serve as a benchmark for comparison. The sensor array was then shipped to PSDF to be subjected to the field-testing at PDSF's power plant in the post combustion zone after the thermal oxidizer. After the field-testing, the sensor array was shipped back to SRD for retesting to the benchmark variety of gas mixtures to compare the sensor array's response characteristics from the pre-field tests and the post-field tests. A comparison of the pre-field test data and the first post-field test data indicate a change in the sensor's response magnitude between the pre- and post-field tests. In order to determine if the response change was due to the 
field-testing, the sensors were shipped back to PSDF and run for a couple of days consecutively. These same sensors were then shipped back to SRD to be retested in a SECOND post-field test.

The results show that although there is a change in sensor responses before and after the field testing, once the field testing occurs, the sensor response stabilizes and respond and recovery reliably. This is evident in the low PFA of 3.5\%. Furthermore, the sensors respond very similarly to the benchmark test for both the first post-field test and the second post-field test.

Taking these results, in conjunction with the reliable sensor performance in the long-term in-house testing ( $>4$ years), it is expected that the sensors underwent a pre-conditioning immediately during the field-testing. Once this conditioning takes place, the sensors are still operational and then become very stable as seen by comparing the similarities in the sensors' responses to the $1^{\text {st }}$ and $2^{\text {nd }}$ post-field testing. SRD has analyzed this data and has concluded that in order to determine the factor influencing sensor conditioning, testing needs to be conducted at various sites and the sensors then be subjected to extensive analysis using:

- Scanning electron micoscop (SEM) to produce 3-d images of surface of the sensors todetermine the changes in the structure and thus determine changes in the electronic properties of the semiconductor material. This can be used to check the removal of sensor material or the deposition of any unwanted materials in the flue gas system.

- X-ray Photoelectron Spectroscopy (XPS) methods to determine the chemical composition of the material and thus detect if there have been any changes in the material due to reaction with unknown elements present in flue-gas.

\section{Conclusions}

SRD has developed and tested a prototype at a DOE approved test facility with success in both classifying and estimating concentrations of coal-fired combustion gas constituents such as carbon monoxide, carbon dioxide, ammonia, hydrogen chloride and nitrogen oxide. SRD's prototype has shown reliable operation in the post combustion section of the power plant with detection times $<25$ seconds and very low false alarm rates $(<4 \%)$. In addition, SRD's concentration estimator performed exceedingly well given that SRD had a very sparse discrete set of concentration values on which they had to base their estimates. After an initial conditioning of the sensor array upon exposure to the actual post combustion environment, the sensor array remained stable and performed very reliably while operating in situ to the post-combustion with no additional conditioning or degradations in the response kinetics.

In the course of the long-range field testing, SRD has also identified the need to conduct field-tests in a variety of different scenarios (facilities) due to the following reasons,

- Optimizing the sensors' preconditioning parameters coincide with actual field test conditions,

- Develop a training database that would increase the resolution of the concentration estimation algorithm, 
- Identify other hardware changes required to develop a prototype capable of being deployed as a commercial product by testing at different facilities having different environmental conditions, and

- Expanding the sensor array to monitor for additional combustion and syngas compounds to canvas a broader base of power plant conditions with a single CEM.

In summary, SRD's prototype has demonstrated a low-cost alternative to monitoring flue gas emissions, capable of real-time monitoring and measuring of combustion gas byproducts in situ to the post-combustion corrosive, high temperature environment. 